\section{MS13 P05}

Synthesis, Structure and Magnetic Properties of New 1D and 2D Manganese Azido Complexes Vratislav Langer $^{\mathrm{a}}$, Morsy A.M. Abu-Youssef ${ }^{\mathrm{b}}$, Albert Escuer ${ }^{\mathrm{c}}$, Alshima'a A. Massoud ${ }^{\mathrm{a}}$, ${ }^{a}$ Environmental Inorganic Chemistry, Department of Chemical and Biological Engineering, Chalmers University of Technology, Sweden. ${ }^{b}$ Chemistry Department, Faculty of Science, Alexandria University, Egypt. ${ }^{c}$ Departament de Química Inorgànica and Institut de Nanociència i Nanotecnologia de la Universitat de Barcelona, Spain.

E-mail: langer@,chalmers.se

\section{Keywords: manganese; azide, magnetic complexes}

The use of azide ion as extremely versatile ligand in coordination chemistry is very interesting due to its ability to coordinate to transition metal atoms in different ways, for example as a terminal, or as a bridging ligand between metal atoms. Azide can bridge two paramagnetic centers either in an 'end-on' $\mu-\left(1,1-\mathrm{N}_{3}\right)$ fashion or an 'end-to-end' $\mu-\left(1,3-N_{3}\right)$ fashion, depending on the steric and electronic requirements of the other co-ligands present in the complex. Generally, the $\mu-\left(1,3-\mathrm{N}_{3}\right)$ azide bridge is known for its strong antiferromagnetic interaction while the $\mu$ $\left(1,1-\mathrm{N}_{3}\right)$ connection mode shows a strong ferromagnetic interaction. Recently we have synthesized a number of new polymeric derivatives of the (azido) $\mathrm{Mn}^{\mathrm{II}}$ system which have been structurally and magnetically characterized. The magnetic analysis for 1D- $\left[\mathrm{Mn}\left(\mathrm{H}_{2} \mathrm{O}\right)(\mu-\right.$ $\left.\mathrm{N}_{3}\right)\left(\mathrm{N}_{3}\right)$ (quinaz) $]_{n}$ (1), 2D- $\left[\mathrm{Mn}\left(\mu-\mathrm{N}_{3}\right)_{2}(\text { quinaz) })_{2}\right]_{n}$ (2) and 1D- $\left[\mathrm{Mn}_{2}\left(3 \text {-ampy) } 4\left(\mu-\mathrm{N}_{3}\right)_{2}\left(\mathrm{~N}_{3}\right)_{2}\left(\mathrm{H}_{2} \mathrm{O}\right)_{2}\right]_{n}\right.$, (3) (quinaz = quinazoline and 3 -ampy $=3$ - aminopyridine) reveals moderate antiferromagnetic coupling, while the magnetic susceptibility measurements show weak ferromagnetic interactions for the 1D- $\left[\mathrm{Mn}\left(\mu-\mathrm{N}_{3}\right)_{2}(\text { pyzamid })_{2}\right]_{n}$ (4) $($ pyzamid $=$ pyrazineamide $) .[1,2]$

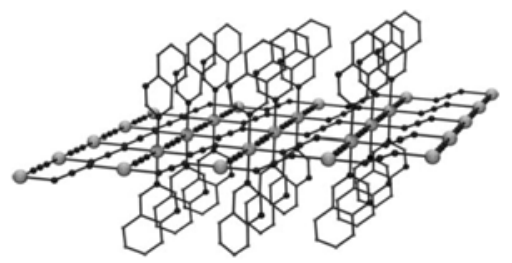

$\left[\mathrm{Mn}\left(\mu-\mathrm{N}_{3}\right)_{2}(\text { quinaz })_{2}\right]_{n}(\mathbf{2})$.

Antiferromagetic interaction in (2)

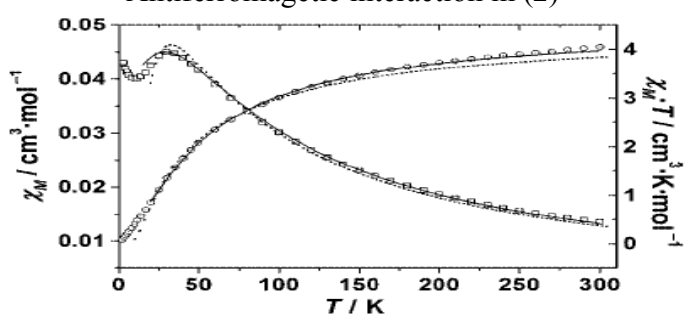

[1] Abu-Youssef M.A.M., Escuer A., Langer V., Eur. J. Inorg. Chem., 2005, 4659.

[2] Abu-Youssef M.A.M., Escuer A., Langer V., Eur. J. Inorg. Chem., 2006, 3177.

\section{MS13 P06}

Synthesis, Structure and Supramolecular Architecture of Bis(Perfluoroaryl) Zinc(II) Adducts of Pyridines and Benzonitriles :Towards Directing NonCentrosymmetric Assembly Without Recourse to Coordination Polymers
Eddy Martin, David L. Hughes and Simon J. Lancaster School of Chemical Sciences and Pharmacy, University of East Anglia, Norwich NR4 7TJ (United Kingdom)

E-mail: e.martin@uea.ac.uk

Keywords: Zinc(II), Fourfold Embraces, Perfluoroaryl-aryl Interactions.

Two series of adducts between benzonitriles ( $\mathrm{L}=$ $\left.\mathrm{C}_{6} \mathrm{H}_{5} \mathrm{CN}, \quad p-\mathrm{C}_{6} \mathrm{H}_{5}-\mathrm{C}_{6} \mathrm{H}_{4} \mathrm{CN}, \quad p-\mathrm{C}_{4} \mathrm{H}_{4} \mathrm{~N}-\mathrm{C}_{6} \mathrm{H}_{4} \mathrm{CN}\right)$ or pyridines $\left(\mathrm{L}=\mathrm{C}_{5} \mathrm{H}_{5} \mathrm{~N}, p-\mathrm{C}_{6} \mathrm{H}_{5} \mathrm{C}_{5} \mathrm{H}_{4} \mathrm{~N}, p-\mathrm{C}_{4} \mathrm{H}_{4} \mathrm{~N}-\mathrm{C}_{5} \mathrm{H}_{4} \mathrm{~N}\right)$ and the highly Lewis acidic perfluoroaryl zinc compounds $\left(\mathrm{C}_{6} \mathrm{~F}_{5}\right)_{2} \mathrm{Zn}$ and $\left(p-\mathrm{C}_{6} \mathrm{~F}_{5} \mathrm{C}_{6} \mathrm{~F}_{4}\right)_{2} \mathrm{Zn}$ have been prepared and structurally characterised. In all but one case the expected tetrahedral adduct was obtained exclusively. When $\mathrm{L}=p$ $\mathrm{C}_{4} \mathrm{H}_{4} \mathrm{~N}-\mathrm{C}_{6} \mathrm{H}_{4} \mathrm{CN}$ a remarkable solvent dependence on the coordination geometry was observed; when crystallised from 1,2-difluorobenzene the expected tetrahedral geometry was formed, whilst from dichloromethane a three coordinate complex was obtained, apparently as a result of an intermolecular $\mathrm{Zn}-\pi$ interaction.

The supramolecular structures of the tetrahedral adducts present a number of surprises. Not least, the perfluoroarylaryl interaction, although present in a number of the lattices, does not predominate and the most significant supramolecular synthons appear to be fourfold aryl and biaryl embraces (Figure 1).

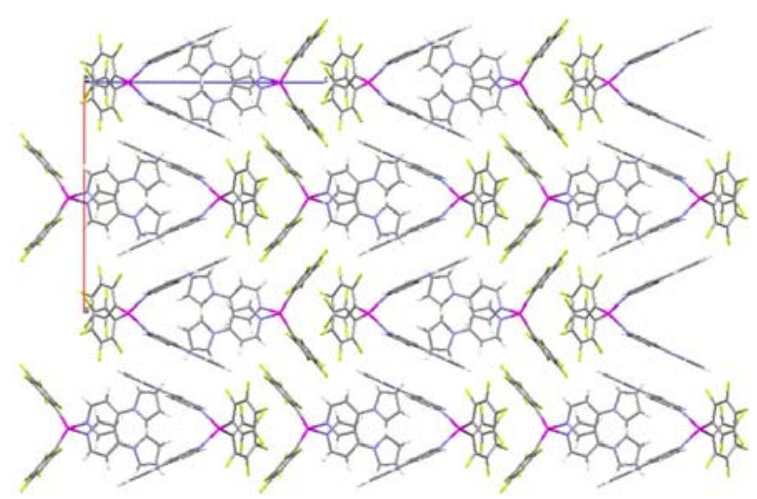

Figure 1. View of the packing of $\left(p-\mathrm{C}_{4} \mathrm{H}_{4} \mathrm{~N}\right.$ $\left.\mathrm{C}_{5} \mathrm{H}_{4} \mathrm{~N}\right)_{2} \mathrm{Zn}\left(\mathrm{C}_{6} \mathrm{~F}_{5}\right)_{2}$, illustrating the opposing columns.

We are currently exploring whether these columns are conserved in co-crystalline materials and whether manipulation of structures of this type can be used to engender non-centrosymmetric architectures.

MS13 P07
Isostructurality in trivalent metal
tris(benzoylacetonates) Vladimir Stilinović and Branko
Kaitner, Department of
University of Zagreb, Zagrab, Croatia. E-mail:
vstilinovic@chem.pmf.hr

Keywords: isostructurality, pseudopolymorphism, metal diketonates

Isostructurality is a similarity of the spatial arrangement of molecules off different compounds in their crystal structures. A prerequisite for isostructurality of two compounds is isometry of their molecules. This is best achieved for molecules which differ only in one or few core atoms, while the surface of the molecule remains mostly unchanged [1]. A very good example of such 
systems are tris(diketonate) coordination compounds of trivalent metals. This was noticed as early as 1926 when has been noted that the crystal structures of trivalent metal pentane-2,4-dionato complexes of various metals appear to be grouped in several isomorphous series [2]. If the metal atom is coordinated by asymmetrical diketonate, two different isomers (facial and meridial) are possible. Our work concentrated on compounds where trivalent metals are coordinated by 1-phenylbutane-1,3-dionato ligands which were studied by single crystal X-ray diffraction and thermal analysis. The meridial complexes of iron(III), manganese(III), chromium(III) were already reported to be isomorphous based on their powder diffraction patterns [3]. We have shown that thay crystallize in the monoclinic system, space group $P 2_{1} / c$. The only facial isomers which could be isolated where those of chromium(III) and cobalt(III) complexes. They were both found to crystallize in two pseudopolymorphic modifications. Pure compounds crystallize in the space group $P-1$ with two molecules in the asymmetric unit. The crystal structures of the chromium and cobalt compounds are almost identical. Under same crystallization conditions, both compounds can also crystallize as hydrates. The hydrates crystallize in the space group $R-3$ with 12 molecules per unit cell. The two symmetrically independent molecules in the structure differ in the mode of hydratation. As is the case with the triclinic modifications, the trigonal modifications of both chromium and cobalt compounds are almost perfectly isostructural

[1] A. Kálmán, L. Párkányi, G. Argay, Acta Cryst. (1993) B49, 1039.

[2] W. T. Astbury, Proc. Roy. Soc. (1926) 28, 313.

[3] R. C Fay, T. S. Piper, J. Am. Chem. Soc. (1962) 84, 2303.

\section{MS13 P08}

Naphthyridines as building blocks: the helix structure of 2-N-acetylamino-7-methyl-1,8-naphthyridine. Laura Torre-Fernández $^{\mathrm{a}}$, Santiago García-Granda ${ }^{\mathrm{a}}$, Shyamaprosad Goswami ${ }^{\mathrm{b}}$, ${ }^{a}$ Departamento de Química Física y Analítica, University of Oviedo, (Spain). ${ }^{b}$ Departament of Chemistry, Department of Chemistry, Deemed University, West Bengal (India).

E-mail: 1tf@fq.uniovi.es

Keywords: hydrogen bonding, supramolecular, Naphthyridines

Multiple hydrogen-bonded assemblies in biological systems are important for the formation of the DNA double helix [1], [2] and protein helical structures [3]. It is interesting to further explore the possibility of multiple hydrogen-bonding in naphthyridines stabilizing the catemers especially those giving rise to helical structures [4].

The 1,8-naphthyridine system functionalized at positions 2 and/or 7 are promising for supramolecular architectures although they are not often used. We report the crystal molecular structure including the supramolecular selfassembly of one of this naphthyridines, 2-N-acetylamino7-methyl-1,8-naphthyridine with helical structure formed by both helices of opposed chirality, P and M, this could lead to helix structures. Interestingly, the terminal points i.e. the amide proton $(\mathrm{N}-\mathrm{H})$ and ring nitrogen $(\mathrm{N} 3)$ take part in hydrogen bonding and a helical structure result for this compound. Non-classical hydrogen bond interactions are shown in between $\mathrm{N} 2 \cdots \mathrm{H} 1-\mathrm{C} 11$ and $\mathrm{N} 2 \cdots \mathrm{H} 01-\mathrm{C} 1$.
Other two normal type of hydrogen bonds are found between $\mathrm{N} 1-\mathrm{H} 2 \cdots \mathrm{N} 3$ and $\mathrm{N} 3 \cdots \mathrm{H} 2-\mathrm{N} 1$ which are the key bond in the formation of single helical structure. An interlayer interaction is found between the interaction of C5$\mathrm{H} 6 \cdots \mathrm{O} 1$

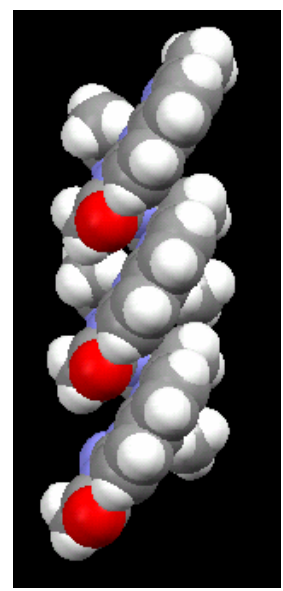

Fig.1. View illustrating the selfassembling hydrogen-bonded helices.

[1] Yoder, M. D.; Keen, N. T.; Jurnak, F. Science, 1993, 260, 1503

[2] Raetz. C. H. R.; Roderick, S. L. Science, 1995, 270, 997.

[3] Strobel, S.; Doucette-Stamm, L.; Riba, L.; Housman, D.; Dervan, P. Science, 1991, 254, 1639.

[4] Goswami, S. P.; Mukherjee, R.; Mukherjee, R; Jana, S.; Maity, A. C. A.; Adak, K. Molecules, 2005, 10, 929.

\section{MS13 P09}

Synthesis and Characterization of New Cerium and Chromium Compounds Barbara M. Casari ${ }^{\mathrm{a}}$, Vratislav Langer ${ }^{\mathrm{b}},{ }^{\mathrm{a}}$ Department of Chemistry, Inorganic Chemistry, Göteborg University, SE-412 96 Göteborg, Sweden. ${ }^{b}$ Environmental Inorganic Chemistry, Department of Chemical and Biological Engineering, Chalmers University of Technology, SE-41296 Göteborg, Sweden.

E-mail: casari@chem.gu.se

Keywords: Mixed valence, Cerium compounds, Chromium compounds

Syntheses and structural characterization of the compounds $\alpha-$ and $\beta-\mathrm{Ce}\left(\mathrm{SO}_{4}\right)_{2} \cdot 4 \mathrm{H}_{2} \mathrm{O}, \mathrm{Ce}_{2}\left(\mathrm{SO}_{4}\right)_{3} \cdot 4 \mathrm{H}_{2} \mathrm{O}$, $\beta-\mathrm{Ce}_{2}\left(\mathrm{SO}_{4}\right)_{3} \cdot 8 \mathrm{H}_{2} \mathrm{O}, \mathrm{K}_{5} \mathrm{Ce}_{2}\left(\mathrm{SO}_{4}\right)_{6} \cdot \mathrm{H}_{2} \mathrm{O}, \mathrm{K}_{2} \mathrm{Ce}\left(\mathrm{SO}_{4}\right)_{3} \cdot \mathrm{H}_{2} \mathrm{O}$, $\mathrm{K}_{5} \mathrm{Na}\left[\mathrm{Ce}_{2}\left(\mathrm{SO}_{4}\right)_{6}\right], \mathrm{CrCe}(\mathrm{III})_{7} \mathrm{Ce}(\mathrm{IV})_{6}\left(\mathrm{HSO}_{4}\right)_{6}\left(\mathrm{SO}_{4}\right)_{21} \cdot 75 \mathrm{H}_{2}$ $\mathrm{O} \mathrm{K}_{6}\left[\mathrm{Ce}\left(\mathrm{HSO}_{4}\right)_{2}\left(\mathrm{SO}_{4}\right)_{4}\right] \cdot \mathrm{H}_{2} \mathrm{O}, \mathrm{A}_{2}\left[\mathrm{CrCl}_{5}\left(\mathrm{H}_{2} \mathrm{O}\right)\right],\left(\mathrm{A}=\mathrm{NH}_{4}\right.$, $\mathrm{K}, \mathrm{Rb}, \mathrm{Cs}), \mathrm{NH}_{4} \mathrm{Cr}\left(\mathrm{CrO}_{4}\right)_{2}$ and $\mathrm{K}_{2} \mathrm{CrSO}_{7}$ are presented. The crystal structures have been determined from single crystal X-ray data and the thermal behaviours have been studied by TG, DSC and X-ray powder thermodiffractometry. The decomposition of $\mathrm{Ce}\left(\mathrm{SO}_{4}\right)_{2}$, into the final product $\mathrm{CeO}_{2}$, proceeds through intermediate $\mathrm{xCeO}_{2} \cdot \mathrm{yCe}\left(\mathrm{SO}_{4}\right)_{2}$ species. However, during the oxidative decomposition of $\mathrm{Ce}_{2}\left(\mathrm{SO}_{4}\right)_{3}$ into $\mathrm{CeO}_{2}$, small amount of $\mathrm{CeO}\left(\mathrm{SO}_{4}\right)$ is produced.

The four salts of the catalytically active $\left[\mathrm{CrCl}_{5}\left(\mathrm{H}_{2} \mathrm{O}\right)\right]^{2-}$ complex are prepared by different methods and reaction pathways are suggested. These compounds are composed of $\left[\mathrm{CrCl}_{5}\left(\mathrm{H}_{2} \mathrm{O}\right)\right]^{2-}$ units connected by $\mathrm{O}-\mathrm{H} \cdots . . \mathrm{Cl}$ hydrogen bonds and a counter ion framework. Further, for the first time, a mixed-valence chromium oxide has been synthesized starting from $\mathrm{CrO}_{3}$ in water solution. The reduction of the $\mathrm{Cr}(\mathrm{VI})$ into $\mathrm{Cr}(\mathrm{III})$ is presumably promoted by the oxidation of $\mathrm{Ce}(\mathrm{III})$. Among the mixed- 